\title{
Atmospheric Radiation Measurement Program Climate Research Facility Operations Quarterly Report
}

July 1 - September 30, 2005

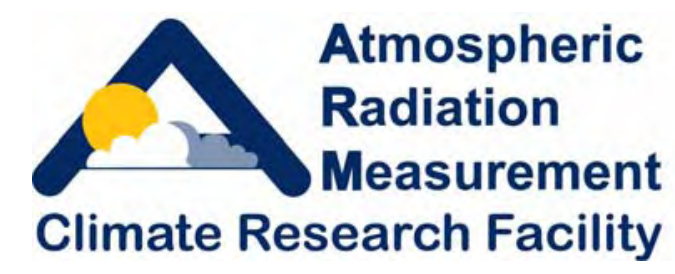

Work supported by the U.S. Department of Energy,

Office of Science, Office of Biological and Environmental Research 


\section{Contents}

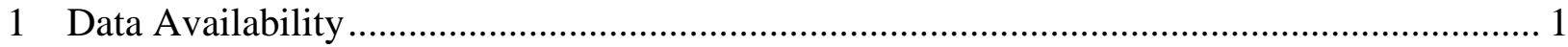

2 Site Visit Requests, Archive Accounts, and Research Computer Accounts............................ 2

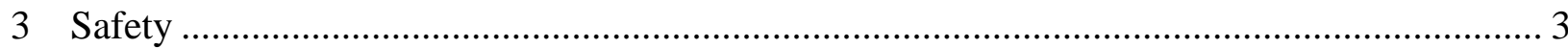

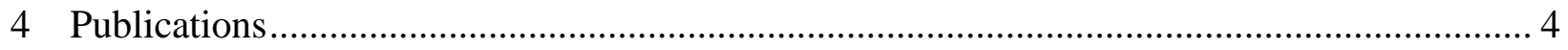

\section{Tables}

1 Operational Statistics for the Fixed ACRF and AMF Sites for the Period July 1 -

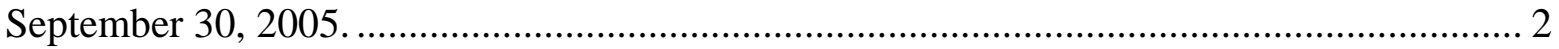

2 Summary of ACRF User Site Visits, Archive Accounts, and Research Computer Accounts for the October 1, 2004 - September 30, 2005................................................... 3

3 Consecutive Days of Injury-Free Operation, * July 1 - September 30, 2005..................... 4

4 Consecutive Days Since the Last Recordable Lost Time Incident or Property Damage Incident, October 1998 - September 2004......................................................................... 4

5 Number of Publications that Use ACRF Data................................................................. 5 


\section{Atmospheric Radiation Measurement Program Climate Research Facility Operations Quarterly Report July 1 - September 30, 2005}

\section{Data Availability}

Description. Individual raw data streams from instrumentation at the ACRF fixed and mobile sites are collected and sent to the Data Management Facility (DMF) at PNNL for processing in near real time. Raw and processed data are then sent daily to the ACRF Archive, where they are made available to users. For each instrument, we calculate the ratio of the actual number of data records received daily at the Archive to the expected number of data records. The results are tabulated by (1) individual data stream, site, and month for the current year and (2) site and fiscal year dating back to 1998.

The DOE requires national user facilities to report time-based operating data. The requirements concern the actual hours of operation (ACTUAL); the estimated maximum operation or uptime goal (OPSMAX), which accounts for planned downtime; and the VARIANCE [1 (ACTUAL/OPSMAX)], which accounts for unplanned downtime. The OPSMAX time for the third quarter for the Southern Great Plains (SGP) site is 2,097.6 hours (0.95 × 2,208 hours this quarter). The OPSMAX for the North Slope Alaska (NSA) site is 1,987.2 hours $(0.90 \times 2,208)$, and that for the Tropical Western Pacific (TWP) site is $1,876.8$ hours $(0.85 \times 2,208)$. The OPSMAX time for the ARM Mobile Facility (AMF) is $2,097.6$ hours $(0.95 \times 2,208)$. The differences in OPSMAX performance reflect the complexity of local logistics and the frequency of extreme weather events. It is impractical to measure OPSMAX for each instrument or data stream. Data availability reported here refers to the average of the individual, continuous data streams that have been received by the ACRF Archive. Data not at the Archive are caused by downtime (scheduled or unplanned) of the individual instruments. Therefore, data availability is directly related to individual instrument uptime. Thus, the average percent of data in the Archive represents the average percent of the time (24 hours per day, 92 days for this quarter) the instruments were operating this quarter.

Summary. Table 1 shows the accumulated maximum operation time (planned uptime), the actual hours of operation, and the variance (unplanned downtime) for the period July 1 through September 30, 2005, for the fixed sites and the AMF. The fourth quarter comprises a total of 2,208 hours. For all fixed sites, the actual data availability (and therefore actual hours of operation) met or exceeded the operational goal for the fourth quarter of Fiscal Year (FY) 2005. For the mobile facility, an instrument problem caused the actual data availability to be below the operational goal but within acceptable variance. The aggregate average of actual data availability for the fixed and mobile sites slightly exceeded the aggregate operational goal for this period. 
Table 1. Operational Statistics for the Fixed ACRF and AMF Sites for the Period July 1 - September 30, 2005.

\begin{tabular}{|c|c|c|c|c|c|}
\hline & \multicolumn{3}{|c|}{ Hours Of Operation } & \multicolumn{2}{c|}{ Data Availability } \\
\hline Site & Opsmax & Actual & Variance & Goal & Actual \\
\hline NSA & $1,987.20$ & $1,994.49$ & -0.004 & 0.90 & $\mathbf{0 . 9 0}$ \\
\hline SGP & $2,097.60$ & $2,104.89$ & -0.004 & 0.95 & $\mathbf{0 . 9 5}$ \\
\hline TWP & $1,876.80$ & $1,957.83$ & -0.043 & 0.85 & $\mathbf{0 . 8 9}$ \\
\hline AMF & $2,097.60$ & $2,031.36$ & +0.032 & 0.95 & $\mathbf{0 . 9 2}$ \\
\hline Site Average & $\mathbf{2 , 0 1 4 . 8 0}$ & $\mathbf{2 , 0 2 2 . 1 4}$ & $\mathbf{- 0 . 0 0 5}$ & $\mathbf{0 . 9 1}$ & $\mathbf{0 . 9 2}$ \\
\hline
\end{tabular}

\section{Site Visit Requests, Archive Accounts, and Research Computer Accounts}

Description. The Site Access Request System is a web-based database used to track visitors to the fixed sites, all of which have facilities that can be visited. The NSA site has the Barrow and Atqasuk facilities. The SGP site has 1 central facility, 23 extended facilities, 4 boundary facilities, and 3 intermediate facilities. The TWP site has the Manus, Nauru, and Darwin facilities. The AMF currently represents one facility. In addition, users who require data more timely than that provided by the ACRF Archive can request an account on the local site data system. The eight research computers are located at the Barrow and Atqasuk facilities; the SGP central facility; the TWP Manus, Nauru, and Darwin facilities; the DMF at PNNL; and the AMF (currently in Point Reyes, California). This report provides the cumulative numbers of visitors and user accounts by site for the period October 1, 2004 - September 30, 2005.

The DOE requires national user facilities to report facility use by total visitor days-broken down by institution type, gender, race, citizenship, visitor role, visit purpose, and facility - for actual visitors and for active user research computer accounts. During this reporting period, the ACRF Archive did not collect data on user characteristics in this way. Work is under way to collect and report these data.

Research computer accounts are counted in the same manner as for the ACRF Archive accounts: an individual is counted as only one unique user per site, even though he or she opens and closes an account several times to obtain different data at one or more sites. However, site visitors are counted each time they visit, because many visitors participate in multiple, unrelated experiments or events.

Also, users that visit sites can connect their computer or instrument to an ACRF network, which requires an on-site device account. Remote (off-site) users can also have remote access to any ACRF instrument or computer system at any ACRF site, which requires an off-site device account. These accounts are also tracked. 
All user accounts are established for period of up to one year and must be renewed annually. To report users, we counted the number of active users for the previous 12 months during the last month of the quarterly reporting period.

Summary. Table 2 shows the summary of cumulative users for the period October 1, 2004 September 30, 2005. For the fourth quarter of FY 2005, the SGP site had a large increase in the number of visitors associated with the Aerosol Lidar Validation Experiment IOP in September. The NSA site had a large increase in the number of visitors in associated with the Boundary Layer Cloud IOP in July. The TWP site also had a large number of visitors at Darwin in preparation for the Tropical Warm Pool International Cloud Experiment IOP that starts in January 2006. There was also a large increase in the numbers of visitors associated with a series of intensive IOPs during July as part of the AMF during its deployment at Point Reyes, California. The number of archive accounts also increased, primarily due to the new data available from research campaigns conducted this quarter.

Table 2. Summary of ACRF User Site Visits, Archive Accounts, and Research Computer Accounts for the October 1, 2004 - September 30, 2005.

\begin{tabular}{|l|c|c|c|c|c|c|c|}
\hline \multicolumn{1}{|c|}{ Site } & Visitors & $\begin{array}{c}\text { Visitor } \\
\text { Days }\end{array}$ & $\begin{array}{c}\text { On-Site } \\
\text { Device } \\
\text { Accounts }\end{array}$ & $\begin{array}{c}\text { Off-Site } \\
\text { Device } \\
\text { Accounts }\end{array}$ & $\begin{array}{c}\text { Research } \\
\text { Accounts }\end{array}$ & $\begin{array}{c}\text { Archive } \\
\text { Accounts }\end{array}$ & $\begin{array}{c}\text { Total } \\
\text { Users }\end{array}$ \\
\hline NSA & 165 & 929 & 22 & 27 & 32 & 215 & $\mathbf{4 6 1}$ \\
\hline SGP & 247 & 1,530 & 17 & 33 & 28 & 472 & $\mathbf{7 9 7}$ \\
\hline TWP & 104 & 268 & 6 & 18 & 20 & 163 & $\mathbf{3 1 1}$ \\
\hline AMF & 116 & 941 & 6 & 18 & 12 & 27 & $\mathbf{1 7 9}$ \\
\hline DMF & & & & & 25 & & $\mathbf{2 5}$ \\
\hline Total & 632 & 3,668 & 51 & 96 & 117 & 877 & $\mathbf{1 , 7 7 3}$ \\
\hline
\end{tabular}

\section{Safety}

For reporting purposes, the three ACRF Sites and AMF operate 24 hours per day, 7 days per week, and 52 weeks per year. Time is reported in days instead of hours. If any lost work time is incurred by any employee, it is counted as a workday loss. Table 3 reports the consecutive days since the last recordable or reportable injury or incident causing damage to property, equipment, or vehicle for the period July 1 - September 30, 2005. There were no lost workdays for the fourth quarter of FY 2005. 
Table 3. Consecutive Days of Injury-Free Operation, * July 1 - September 30, 2005.

\begin{tabular}{|c|c|c|c|c|}
\hline ES\&H Category & NSA & SGP & TWP & ARM \\
\hline Days Worked without a Lost Time Incident & 92 & 92 & 92 & 92 \\
\hline $\begin{array}{l}\text { Days Worked without a Recordable Accident (Medical } \\
\text { Treatment Case) }\end{array}$ & 92 & 92 & 92 & 92 \\
\hline Days Worked without a Property-Damage Incident & 92 & 92 & 92 & 92 \\
\hline Days Worked without a Reportable Loss to Vehicles & 92 & 92 & 92 & 92 \\
\hline
\end{tabular}

This quarterly report also includes historical safety performance data, which is provided in Table 4 and summarizes safety statistics for the period October 1, 1998 - September 30, 2005.

Table 4. Consecutive Days Since the Last Recordable Lost Time Incident or Property Damage Incident, October 1998 - September 2004.

\begin{tabular}{|l|c|c|c|c|}
\hline \multicolumn{1}{|c|}{ ES\&H Category } & NSA & SGP & TWP & ARM \\
\hline Days Worked without Lost Time Incident & 2,555 & $1,393^{*}$ & 2,555 & 639 \\
\hline $\begin{array}{l}\text { Days Worked without a Recordable Accident (Doctor } \\
\text { Case) }\end{array}$ & 2,555 & $1,393^{*}$ & 2,555 & 639 \\
\hline Days Worked without a Property-Damage Incident & 2,555 & 2,555 & 2,555 & 639 \\
\hline Days Worked without a Reportable Loss to Vehicles & 2,555 & 2,555 & 2,555 & 639 \\
\hline
\end{tabular}

*SGP has had three lost work day cases:

FY 1998: 2 lost days restricted work for lower back sprain;

FY 1999: 14 lost days for fracture of wrist (slipped and fell on ice after hail storm); and FY 2000: 162 lost days and 130 restricted days to alleged injury of congenital defect to back.

\section{Publications}

Description. As an additional measure of performance, this quarterly report includes the number of publications that are based on ACRF data, with emphasis on this year's contribution but also summarizing historical data, collection of which began in 1990. The publication categories are (1) abstracts or presentations at conferences, (2) technical reports, (3) books, (4) book chapters, (5) journal articles, and (6) papers in conference proceedings.

Summary. Table 5 shows the number of publications by category for 1990 through September 2004, the number of publications for FY 2005, and the total of publications for 1990 through September 2005. 
Table 5. Number of Publications that Use ACRF Data.

\begin{tabular}{|l|c|c|c|}
\hline \multicolumn{1}{|c|}{ Category } & 1990-September 2004 & FY 2005 & 1990-September 2005 \\
\hline Abstracts or Presentations & 1,445 & 241 & 1,686 \\
\hline Technical Reports & 74 & 54 & 128 \\
\hline Books & 2 & 1 & 3 \\
\hline Book Chapters & 47 & 4 & 51 \\
\hline Journal Articles & 1,422 & 109 & 1,531 \\
\hline Conference Papers & 1,541 & 111 & 1,652 \\
\hline
\end{tabular}

